\title{
Psychohermeneutics of graffiti: external and internal loci of control
}

\author{
Valentina Kolmakova ${ }^{1 *}$, and Denis Shalkov ${ }^{1}$ \\ ${ }^{1}$ Don State Technical University, Gagarina sq., 1, Rostov-on-Don, 344003, Russia
}

\begin{abstract}
The article examines the features of the expression of psychoemotional conflict within a person within the framework of external and internal loci of control through the creation of graphic art objects. The authors argue that communicative strategies for resolving problems in stressful situations and seeking social support are associated with the question of the individual's ability to independently solve emerging problem situations and find internal resources to overcome them by releasing psychoemotional stress, based on the structure of the cognitive sphere of a person, the characteristics of his perception and thinking. Typical external semantics of graffiti consists in an attempt to convince others of the hopelessness of being. The internal locus of control is associated with the conceptual sphere of social activity and is embodied in a wide variety of imperative forms, including a call, order, request, advice, and so on. In other words, the psycho-hermeneutics of graffiti is conditioned, on the one hand, by communicative and pragmatic strategies of social empathy (internal locus of control), and, on the other hand, by the conflict of the individual with society and the desire for spiritual and moral escapism, escape from reality to self-isolation and loneliness (external locus of control). The study proposes a classification of graphic art objects, which is based on the form of public expression of the individual's inner world, which is associated with the implementation of the compensatorypragmatic function of graffiti as a universal code of modern urban communication.
\end{abstract}

\section{Introduction}

The concept of «locus of control» was introduced by J. Rotter in the framework of behaviorism - one of the leading directions in psychological science. Locus of control is interpreted as a stable personal characteristic of the cognitive sphere of a person - a certain feature of his perception and thinking, which is weakly amenable to change, but is finally formed as a result of socialization processes [1]. According to J. Rotter, the locus of control is a generalized expectation of the extent to which an individual controls reinforcements in his life.

The purpose of this study is to consider the features of the expression of psychoemotional conflict inside a person within the framework of external and internal loci

\footnotetext{
*Corresponding author: vvklm07@mail.ru
} 
of control through the creation of graphic art objects. From the point of view of psychohermeneutics as a universal theory of understanding, graffiti is the optimal way to «declare yourself» using a name (tag), image or inscription. At the level of consciousness and subconsciousness, the recipient perceives the text of the graphic art object as someone else's subjectivity, focused on understanding the meaning inherent in it. At the same time, the semantic connections, according to the supporters of the hermeneutic method, should be disclosed first of all in the object of interpretation, since it is fundamentally important not only what the author himself wanted to say, but also what was objectively reflected in the text [2].

Proponents of a narrow understanding of graphic art objects divide them into dipinty and graffiti proper. The word «graffiti» comes from the Italian verb «graffiare» - «to scratch», the term «dipinti» refers to inscriptions made with spray paint. At present, graphic art objects are considered to be any images or inscriptions, scribbled, written or painted with paint (ink) on walls and other surfaces, regardless of the degree of professionalism of the application of images. In addition to walls, it can be cars, money, railroad cars, etc. Graffiti in a broad sense can include any kind of street wall painting: from single words to exquisite drawings and creolized texts.

There is a whole complex of psychological motives that induce a writer to create graffiti [3]. Graphic art objects are not only one of the methods of communication that implements a number of coping strategies (strategies for solving problems, looking for social support or avoidance), but also a form of public expression of a person's inner world, which is associated with the implementation of the compensatory communicative-pragmatic function of graffiti.

\section{Materials and methods}

From a psychological point of view, the graffiti subculture, like any other subculture, unites people with unresolved or unrecognized intrapersonal conflicts [4]. Needs that are not realized in objective reality form a psychoemotional conflict within a person, which can lead to self-destruction and a destructive behavioral trajectory. It is no coincidence that a number of researchers often identify the process of applying graffiti with an act of vandalism and manifestation of deviant behavior. Graffiti is a public and spontaneous expression of an individual's inner world. Exposing himself to communicative interaction with other individuals in a positive or negative way, the graffiti artist, on the one hand, seeks to feel the involvement of objective reality, and on the other, to overcome psychological complexes and intrapersonal experiences, often suppressed and hidden.

The first motive for creating graffiti relates to an external locus of control. This type of locus is observed in individuals who shift responsibility for what is happening to others and external circumstances, which are often assessed as fatal and insurmountable. The tendency towards the specified locus of control manifests itself in uncertainty, anxiety, imbalance, sometimes in suspicion and aggressiveness, which finds expression in the meaningful and para-linguistic content of graphic art objects.

The second motive for creating graffiti is due to the internal locus of control, which manifests itself in the ability of the individual to independently bear responsibility for the decisions in life: graffiti artists of this psychotype are convinced of the productivity of influencing external circumstances and consider it possible to transform them. The communicative message of inscriptions and drawings, broadcast in the public space, correlates with a purely pragmatic goal - to influence the behavior of the collective recipients of graffiti. 


\section{Results}

From the point of view of modern linguistic archeology, graphic art objects in a broad sense mean any inscriptions that are applied to a wide variety of surfaces. Considering the scope of graffiti as a universal code of modern urban communication, it is advisable to propose the following classification of graphic art objects according to their location:

1) «classic» loci:

- graffiti on the walls of residential buildings, garages, government institutions and industrial premises;

- on fences and barriers;

- on the windows of shops and service establishments;

- at trade stalls, kiosks;

- at infrastructure facilities (power transmission posts, containers for collecting solid municipal waste);

- in the entrances;

- on an asphalt surface (in front of residential buildings, in pedestrian areas, on the roadway);

- at bus stops;

- on monuments and memorial complexes;

2) «extreme» («marginal») zones:

- basements;

- ceilings;

- windows;

- surfaces of abandoned or unfinished premises;

3) banknotes;

4) surfaces of vehicles (personal cars, railroad trains, public transport);

5) pieces of furniture (more often in shopping malls and educational institutions):

- tables;

- chairs;

- wardrobes.

Consider the graffiti depicted in the most popular places - on the walls of buildings and structures. To analyze the dynamics and ways of representing external and internal loci of control as the main communicative and psychological behavioral strategies, examples of graphic art objects from different cities of Russia were taken (Rostov-on-Don, Azov, Taganrog, Vladimir, Belgorod, Tver', Cheboksary, Moscow, St. Petersburg, Volgograd, Kaluga, etc.).

By resorting to the creation of wall paintings, artists with an internal locus of control put in them a direct call for social activity, which is realized in a wide variety of forms [5]. This may be an appeal to the authorities, which cannot solve the problems of city improvement: «Kaluga / needs / new / park». (Hereinafter, the spelling and punctuation of the original are kept - V.K., D.Sh.) Or a call to others to make the necessary efforts to achieve their goals, implement ideas and aspirations: «Live / work / create»; «Practice chaotic / good»; «Act / idea without / matters / deed!»; «You can do it»; «I am calm as / the pulse of the dead / Mayakovsky» (with the postscript «Learn / to be / people»); «We can always start over» (the inscription is made in English and Russian); «Moscow / speaks / the others / are working» (the words «Moscow speaks» are written in red, the rest of the phrase is written in black). Some graffiti highlights social issues: «Only death / and utility bills are inevitable» (the letter " $\mathrm{i}$ " in the word «bills» is written in red); «The Mortgage in the Rye» (the inscription correlates with the title of Salinger's novel «The Catcher in the Rye», metaphorically likening the purchase of a house with a mortgage and «the catcher»). 
A communicative strategy for resolving problems in difficult life situations involves the desire to independently overcome the difficulties that arise and find internal emotional forces for this, while maintaining balance, benevolence and independence. Belief in one's own capabilities modifies the verbal row of graffiti, the author of which is a linguistic personality with a prevailing internal locus of control: «To be with the one / who makes you / happy» (the word «with» is crossed out); «Hug / dress warmly» (the word "dress» is crossed out). The presented graph-feats contain corrections of the original text, which manifests the active life position of the graffiti artist who made these changes, as well as his conviction that there is a way out of any, even a dead-end, at first glance, situation: to turn bad into good into the forces of every person.

The internal locus of control is presented in the communicative strategy of seeking social support, when a graffiti communicant, in order to effectively solve a life dilemma, seeks help and support among the immediate environment («Cat, I can no longer live without you»), directly tries to influence the addressee using the strategy verbal aggression («Beast / pay»), or on the contrary, declares the immutable value of human life («The life of a / 40-year-old / drinking, / smoking man / matters»; «Nobody / wants to love / in us / ordinary / person. / A.P. Chekhov»).

Internal communication strategies for coping with a stressful situation are presented in street art objects containing concepts of understanding the meaning of life, determining the place and role of a person in society: as an example, the motivating graffiti « 257 reasons to live» («get a dog», «Fly», «write poetry», «return to sports», «get a grant», «wait for the birthday», «happy life», «scooter», «sun», «ocean», «Petre», «rainbow mountains», «sunset on the Don», «fly to Cuba», «read 45 books», «pet a raccoon», «learn English», «drive a tram», «hug a whale», «take off the mask», «summer forever», «green light», «travel», «love», «overcome fear», «go to London»; «give birth to a son», etc.). Graffiti with internal purposefulness can include interrogative or imperative constructs that have the pragmatism of active intervention in the prevailing circumstances and express a call for active action to resolve problems, as well as affirm the idea that everyone is worthy of their happiness: «Speak only good / or keep silence»; «Kiss me / while we are still / feel something»; «Never give up / piece of meat. / OK» (the address «piece of meat», implements a provocative function, is designed to provoke the addressee to counteract); «May / always / be / happiness»; «Are you a person?»

On the contrary, externally graffiti tends to convey pessimistic sentiments, skepticism about human nature, a sense of devaluation of spiritual and moral guidance: «Soul not / drink» (written: «I drank»); «People are herd / bananas»; «Live in the bedroom area / and do not sleep»; «That would be / wonderful, / but... / erm... »; «Love / No. / Go / Sleep»; «Will we / continue / to turn / to such / disgusting / adults?»; «More and more people / people think / that they can think»; «Pain / wants us / to feel / it».

A special group of graffiti is the inscriptions of patriotic content, which represent the internal pragmatic and psychological intentions of graffiti artists, in other words, their active civic position [6]. For example, the image of a boy in military uniform saluting and the slogan «We Are Proud!» is perceived as a call addressed to the modern generation to always remember and respect the feat of the victors in the Great Patriotic War. The communicative urban space contains whole series of graffiti dedicated to a significant event in Russian history: «Victory / Bought / Blood»; «9th May»; «WWII / 1941-1945»; «70 Years of Victory»; «We remember»; «For Motherland» (inscriptions on garages on the territory of one of the schools in Rostov-on-Don).

The semantics of cultural and historical memory are conveyed by graffiti with images of Russian poets and writers and precedent quotations from their works: «About how many wonderful discoveries we have / Prepares enlightenment spirit / And experience, the son of difficult mistakes, / And a genius, friend of paradoxes... / A. Pushkin»; «Listen! / After all / 
if the stars / light up / means - this / does anyone need?»; «Create, invent, try! / V.V. Mayakovsky»; «Always shine, / Shine everywhere, / Until the last days, / Shine - / and no tacks! / Here is my slogan / and the sun! V. Mayakovsky»; «Jacket / change outside / not enough, comrades! / Turn out / inwardly!»; «In our life / we love only once, / and after that we are looking for / only similar ones / S. Yesenin»; «Evening fields in dew, / Above them - crows... / I bless you on all / four sides! / M. Tsvetaeva»; «Don't get tired / do / do good / A. Chekhov»; «To live / not by lies! / A.I. Solzhenitsyn». The presented graffiti have a dialogical character and, expressing the concept of connection between generations of different eras, acquire not only intimate and personal, but also agitational and invocative communicative intentions: the direct duty of modern society is to preserve immutable spiritual and moral guidelines and moral and ethical and values [7].

Through the creation of graphic street art objects, internals can express their attitude to the internal political events taking place in the country and the corresponding legislative initiatives: «Laws / are blind». A whole wave of the appearance of graphic street art objects was caused by the procedure for amending the Constitution of the Russian Federation in 2020. In one of the graffiti, a negative attitude towards changing the basic law of the country is expressed with the help of the well-known expression «The laws / don't apply / to the fools». Of particular interest is the way of design of the above inscription. Against the background of a gray wall, a girl is depicted from her back, who edits an inscription made in black in red ink: she adds the word «by» to the word form «fools» and crosses out the negative form «don't» crosswise. Conceptual intentions of graffiti acquire the communicative-pragmatic effect of «flickering» of meanings - this is how the evaluative semantics of the phrase is intensified as a result of layering one verbal row of the inscription on another: «The laws / apply / by fools».

The attention of graffiti artists focused on the changes in the life of society and the lives of individual citizens, which were provoked by the COVID-19 pandemic [8]. So, the inscription «COVID-1984» (the numbers «84» are written in black, the rest of the graffiti in red) contains allusions to the dystopian novel «1984» by J. Orwell, which tells about everyday life in conditions of permanent fear and turmoil. The inscriptions dedicated to this topic contain not only anxiety about the future, but also specific instructions on how to behave in the present, being in an emergency situation: «- How can I / help in / fight against / pandemic? // - Go to the / site we are together2020.rf / there is a lot of useful / information»; «Have you heard what / is happening in the world? / There has never been such an epidemic yet! // We can / help if we / comply with the / self-isolation // Yes, and do not forget / about the / personal / protection means»».

Some situational graffiti ironically interpret the environment - the place of localization of the inscription: «Knowledge is power» (in the premises of the liquidated library, the floor of which is strewn with abandoned books); «God / give me / a sign» (on the fence, from behind which you can see recycled road signs); «At least climb the wall» (inscription on the wall under the fire escape leading to the roof).

The desire to get rid of the psychoemotional tension inherent in individuals with an external locus of control contains graffiti depicted on a brick wall and representing a creolized text: «VERY SAD masks / ruffles / UNDER FUN / in the hope that / the mask will grow». The inscription is made on a dark blue-black-red background with all the colors of the rainbow. With the help of multi-colored paints, the graffiti artist, as it were, «disguises» the «sad as cheerful», and the striped letters, demonstrating the eternal dualism of being, represent a graphically realized metaphor of «light» and «dark» stripes in the life of every person.

Diametrically opposite targetings, causing a feeling of hopelessness, symbolizes the graffiti «window in / gray / WORLD»: against the background of a dark gray painted brick wall, a window is schematically depicted, on top of which there is the inscription «window 
in», below - «WORLD» and the word «gray» is written in the upper frame. Typical external semantics of graffiti tries to convince others of the hopelessness of being: there is no way out of the impasse, and the person himself is unable to change anything in his destiny.

A peculiar emotional attitude to the world, balancing on the verge of optimism and pessimism, internal and external loci of control, is expressed by inscriptions of a pseudophilosophical nature, assessing the capabilities of human mind and will in opposition to external circumstances and asserting that a person is the creator of his own destiny [9]: «Dandruff it is / Ashes / of Burning / Mibd»; «Why did you / wake up / today?»; «No / Philosophical Problems / No, Only Anfilada / Linguistic Deadlocks, / caused by the inability of / language to reflect the truth»»); "What does / one wall say / to the other wall? // Meet me / in the corner» (graffiti on walls located perpendicular to each other); "You can do better / and you have time (part of the phrase is done in brown paint), but you / spend all your (and mine) / time, telling eloquently, / how and why (words are written in blue) you cannot (the end of the phrase is in red)»; «Thought can not / be painted over» (inscription over the painted inscription); «As long as it's / worth it»; «Inside / we / more / than / outside»; «A decent person / does nasty things / without pleasure»; «Before entering / think - / are you needed here?» (inscription on a metal door with a padlock); «Nothing inspires / believes a person / as an advance payment».

Often this type of graffiti is built on the principles of a language game or a pun [10]: «The beginning is more promising than the end / the tomato tastes better than the cucumber»; «Don't fall / Spirit / Anywhere»; «See lump sugar / instant-soluble / it's sweet life / sleep fast-moving» (graffiti includes an image of 2 pieces of refined sugar); «Live with your heart / think with your head / eat with your mouth / walk with your feet» (the inscription is made by two graffiti artists: the first two lines are written in white, the rest are added in black).

Extremely interesting things are «corrected» or «supplemented» graffiti, which may belong to two authors with different loci of psychoemotional control - external (pessimistic) and internal (optimistic) [11]: «Believe in / yourself» (fixed by «Door / in yourself»); «Important / Remaining / Man» (corrected to Important / Remaining / SpiderMan); «Someone has been lying for a long time and / seems to continue planning / to lie» (corrected to «Someone has been forced to lie for a long time and, / seems to be planning / lie further. / This should not embarrass anyone»; "This is not / place / for / art» (inscription on the concrete part of the fence) (added «And this is not / place / for your / opinion»); «The bar is closed» (added «... but not broken»); «Inside / we / more / than / outside» (written «Do not exchange / Ocean for puddles»).

Analyzing the frequency thematic groups of graffiti that are contained on banknotes, it should be noted the interaction of external and internal motives that guided their creators: financial well-being is the key to gaining independence and an equivalent of success and personal growth, but material values should not be placed to the top of the pyramid of human needs [12]. Placing inscriptions on banknotes, graffiti artists reinterpret the wellknown units of the Russian phraseological system: «happiness is not in money»; «letting money go down the drain»; «small spool, but expensive», etc.

Among the thematic groups of inscriptions on money, the following can be identified [13]:

1) congratulations, which is associated with the tradition of presenting money as a gift: «Dear Ivan, all the best / best to you and / your family, / you are a good, sympathetic / person, kind, / health to you and your / mom and as soon as possible / demobilization» (on the left side of the bill); "They say happiness is not about money / although everything / depends on money / I wish you a lot of them / But do not lose yourself... » (on the right side of the bill); 
2) poetic miniatures and inscriptions of a philosophical-meditative nature about the frailty of material values: «Knowing no sleep / no rest in the / moon and sunlight, We make / money out of thin air / in order to / again / send them to the wind»; «Wake up / money is not the main thing»; «The price of money / is the time / we spend earning it. / Don't waste your time»; «Do not forget / about / soul»;

3) messages addressed to the subject of adoration: «... We are destined by fate / Meet again / In one of the February days, / I bet on the thirty / first ... / I. Brodsky» (the inscription contains the hashtag «Poems on the money»);

4) notes indicating the purpose of using the money: «Drink me»; «Use me / for buying/ ramen noodles»;

5) inscriptions of socio-political content: «Our children / still live / in this country. / Isn't it time / to change something?»;

6) inscriptions-greetings and inscriptions-messages calling to share the emotional state of the author: «Hello / from / the sunny / Crimea!!!» (with signature);

7) inscriptions that broadcast life experience, worldly wisdom: «Quit smoking / saved / 18,500 rubles / per year».

One of the most popular places for graffiti painting is in cars. The conceptual core of these inscriptions is the public broadcast of the psychoemotional state through the verbalization of both positive and negative emotions [14]. As a result, the author-graffiti artist experiences a kind of catharsis - a process of liberation, resolution of internal conflicts, life's dilemmas and moral purification through self-expression. Among the most frequent thematic groups of graffiti data are the following:

1) congratulations: «Happy birthday» (with the postscript «love»);

2) thanks: «Darling! / Thanks for the Daughter!!»;

3) significant events in his personal life: «I'm going for my daughter!»; «Divorced / Hurray!!! / Freedom!!!»;

4) revenge: «Goat» (on the windshield); «Freak»; «Deer»; «My son is 3 years old / Where is the alimony???»; «I loved you»; «Was this b*ch / worth it?»; «Stupid sheep»;

5) desires: «I want to get married»;

6) appeals: «This car / sometimes / my wife drives / I ask you to understand / and forgive»; «Cheapskate / think about children».

\section{Conclusions}

The data obtained as a result of the psycholinguistic analysis of 300 graffiti reflects the main spheres of their existence and 2 basic loci of control of graffiti authors (internal and external). The distribution of graphic art objects according to the designated communicative-behavioral strategies and areas of placement in absolute numbers and in percentage is presented in Table 1 .

Table 1. Psychohermeneutics of graffiti: internal and external loci of control.

\begin{tabular}{|c|c|c|c|c|}
\hline \multirow[b]{3}{*}{$\begin{array}{c}\text { A place } \\
\text { placement }\end{array}$} & \multicolumn{4}{|c|}{ Loci of control } \\
\hline & \multicolumn{2}{|c|}{ Internal } & \multicolumn{2}{|c|}{ External } \\
\hline & $\begin{array}{c}\text { Number of } \\
\text { graffiti (in } \\
\text { absolute figures) }\end{array}$ & $\begin{array}{l}\text { Number of graffiti } \\
\text { (in percentage) }\end{array}$ & $\begin{array}{c}\text { Number of } \\
\text { graffiti (in } \\
\text { absolute figures) }\end{array}$ & $\begin{array}{l}\text { Number of graffiti } \\
\text { (in percentage) }\end{array}$ \\
\hline «Classic» loci & 80 & 53,3 & 45 & 30 \\
\hline $\begin{array}{c}\text { «Extreme» } \\
(« \text { marginal») zones }\end{array}$ & 31 & 20,7 & 67 & 44,7 \\
\hline Banknotes & 15 & 10 & 9 & 6 \\
\hline Vehicles & 10 & 6,7 & 21 & 14 \\
\hline Furniture items & 14 & 9,3 & 8 & 5,3 \\
\hline Total & 150 & 100 & 150 & 100 \\
\hline
\end{tabular}


The data obtained in the course of the study indicate that graffiti with an internal locus of control is mostly represented in «classical» urban loci, as well as on banknotes and pieces of furniture. This is due to the fact that graffiti artists of this psychotype are convinced of the effectiveness of influencing external circumstances and strive to independently resolve life dilemmas. On the contrary, external graffiti artists, disclaiming responsibility for what is happening and thus trying to neutralize stress factors, often place inscriptions in «extreme» («marginal») zones and on the surfaces of vehicles [15].

Thus, graffiti is one of the unconventional ways of self-expression of its authors - the verbalization of internal psychological impulses and conflicts. Communicative strategies for resolving problems in stressful situations and seeking social support are associated with the question of the individual's ability to independently solve emerging problem situations and find internal resources to overcome them by releasing psycho-emotional stress, based on the structure of a person's cognitive sphere, the characteristics of his perception and thinking. Typical external semantics of graffiti consists in an attempt to convince others of the hopelessness of being, and also proceeds from the idea that a person is not able to change anything in his life and is subject to the influence of objective factors beyond his control. The internal locus of control is associated with the conceptual sphere of social activity and is embodied in a wide variety of imperative forms, including a call, order, request, advice, and so on. In other words, the psycho-hermeneutics of graffiti is conditioned, on the one hand, by communicative and pragmatic strategies of social empathy (internal locus of control), and, on the other hand, by the conflict of the individual with society and the desire for spiritual and moral escapism, escape from reality to self-isolation and loneliness (external locus of control).

\section{References}

1. F.J. Infurna, S.S. Luthar, Clinical Psychology Review, 65, 43-56 (2018), doi: 10.1016/j.cpr.2018.07.003

2. S. López-Rocha, Language and Intercultural Communication, 21(1), 118-131 (2021), doi: 10.1080/14708477.2020.1833900

3. S. M. Croucher, M. Sommier, D. Rahmani, Communication Research and Practice, 1(1), 71-87 (2015), doi: 10.1080/22041451.2015.1042422

4. D. Fletcher, M. Sarkar, European Psychologist, 18(1).01, 12-23 (2013), doi: 10.1027/1016-9040/a000124

5. A.-K. Ward, E. C. Ravlin, B. S. Klaas, R. E. Ployhart, N. R. Buchan, Journal of Applied Psychology, 101(10), 1498-1511 (2016), doi: 10.1037/ap10000144

6. Z.M. Huang, Language and Intercultural Communication, 21(1), 83-101 (2021), doi: 10.1080/14708477.2020.1833898

7. V. Kolmakova, D. Shalkov, O. Baryshnikova, E3S Web of Conferences, 210(8), 18023 (2020) doi: 10.1051/e3sconf/202021018023

8. V. Kazankov, E3S Web of Conferences, 210(8), 20020 (2020), doi: 10.1051/e3sconf/202021020020

9. D. Matsumoto, H. C. Hwang, Cross-Cultural Research, 40 (5), 439-460 (2015), doi: 10.1177/1069397115599542

10. S. Bylkova, D. Shalkov, E3S Web of Conferences, 210(8), 18010 (2020), doi:10.1051/e3sconf/202021018010

11. W.S. Ward, A.F. Southwell, Journal of Intercultural Communication Research, 50(2), 122-145 (2021), doi: 10.1080/17475759.2020.1782970 
12. A. Tashchian, W. R. Forrester, M. Kalama, Journal of International Education Research, 10 (1)1, 29-36 (2014), doi: 10.19030/jier.v10i1.8348

13. D. Shalkov, V. Kolmakova, E. Shilova, Modern Global Economic System: Evolutional Development vs. Revolutionary Leap, 198, 136-144 (2021), doi: 10.1007/978-3-03069415-9_16

14. J. Serfaty, R. Serrano, System, 94, 102342 (2020), doi: 10.1016/j.system.2020.102342.

15. M.-S. Kim, Asian Journal of Communication, 20, 166-180 (2010), doi:10.1080/01292981003693351 